\title{
A FORMAÇÃO DE PROFESSORES DE QUÍMICA NUM PRÉ-UNIVERSITÁRIO POPULAR: UM ESTUDO DE CASO DO PROJETO DE EDUCAÇÃO COMUNITÁRIA INTEGRAR
}

Nicolle RUPPENTHAL Escola Estadual Professora Nadir de Oliveira (ENO)

Várzea Grande, Mato Grosso - Brasil nicolleruppenthal@gmail.com https://orcid.org/0000-0001-9058-5863

Carlos Alberto MARQUES Universidade Federal de Santa Catarina (UFSC) Florianópolis, Santa Catarina-Brasil carlos.marques@ufsc.br https://orcid.org/0000-0002-4024-7695

\begin{abstract}
RESUMO: Este trabalho discute a formação de professores de química em Pré-Universitários Populares (PUPs). Analisado com um estudo de caso, organizou-se um grupo focal, formado por professores de Química atuantes no Projeto Integrar. Os registros das discussões foram analisados por meio da Análise Textual Discursiva, cujas categorias emergentes foram: "O papel do planejamento" e "O desenvolvimento das aulas". O estudo apontou que o Integrar contribui com a formação de professores de Química, os quais demonstraram ênfase no educando enquanto parte do processo educativo, sendo uma tentativa de se distanciar da educação bancária. Os estudantes do Integrar são as pessoas que, apesar de políticas de inclusão e fatores pessoais e/ou sociais, acabaram por serem excluídas do Ensino Superior. Posto isto, o Integrar, como parte do movimento dos PUPs, demonstrou um ensino integrado às lutas sociais, ressaltando, assim, a importância desse movimento para a realidade da educação brasileira.
\end{abstract}

PALAVRAS-CHAVE: Formação de professores. Pré-universitários populares. Ensino de química. 


\title{
THE CHEMISTRY TEACHERS TRAINING IN PRÉ- UNIVERSITÁRIO POPULAR: A FOCUS GROUP IN PROJETO DE EDUCAÇÃO COMUNITÁRIA INTEGRAR
}

\begin{abstract}
This paper debates chemistry techers' training in Pré-Universitários Populares (PUPs). Analysed with a case study, a focus group was organized by chemistry teachers that are active in Projeto Integrar. The conversation was analyzed by discursive textual analysis, whose emerging categories were "The role of planning" and "The classes development". The research pointed out that Integrar contributes to the training of the chemistry teachers, which emphasizes the student in the educational process, and trying to hold off the banking model education. The Integrar's students are people who was excluded from the universities because of several reasons, such as color, gender, sexual orientation, poorness, etc. Hereupon, the Integrar as an important part of PUPs, demonstrated teaching integrated with social struggles, then highlighting the importance of this movement to the Brazilian education.
\end{abstract}

KEYWORDS: Teachers' training. Pré-universitários populares. Chemistry teaching

\section{LA FORMACIÓN DE PROFESORES DE QUÍMICA EN UN PRÉ-UNIVERSITÁRIO POPULAR: UN ESTUDIO DE CASO EN EL PROJETO DE EDUCAÇÃO COMUNITÁRIA INTEGRAR}

RESUMEN: Este artículo discute la formación de profesores de química en Pré-Universitários Populares (PUPs). Hecho un caso de estudio, se organizó un grupo focal de profesores de Química miembros del Projeto Integrar. Los registros de las discusiones se analizaron mediante el Análisis textual discursivo, cuyas categorías emergentes fueron: "El papel de la planificación" y “El desarrollo de las clases". El estudio señaló que Integrar contribuye a la formación de profesores de Química, quienes mostraron un énfasis en el estudiante como parte del proceso educativo, siendo un intento de distanciarse de la educación bancaria. Los estudiantes del Integrar son personas que, por diferentes motivos (color, orientación sexual, pobreza, género, etc.), fueron excluido de la universidad. Dicho esto, Integrar, como parte del movimiento PUPs, demostró la enseñanza integrada con las luchas sociales, enfatizando así la importancia de este movimiento para la realidad de la educación brasileña.

PALABRAS-CLAVE: Formación de profesores. Pré-universitários populares. Profesores de química. 


\section{Introdução}

A discussão pelo direito de acesso à Universidade, embora não seja uma pauta nova, é extremamente atual e começou a se tornar popular a partir da década de 1990, com a mobilização dos cursinhos populares (CASTRO, 2019). Desse clamor popular originou-se a luta das populações excluídas (negros, indígenas, quilombolas, transexuais, trabalhadores, pobres, estudantes de escola pública) para adentrar no ensino superior, iniciando os primeiros Pré-Universitários Populares (PUPs) (BACCHETO, 2003). Apesar de se ter transcorrido quase 30 anos dessa luta, e da instituição da política de cotas através da lei n 12711 (BRASIL, 2012), ainda hoje tais populações permanecem excluídas das universidades. Algo que pode ser percebido na fala do ex-Ministro da Educação, Abraham Weintraub, quando se opõe ao adiamento do ENEM (Exame Nacional do Ensino Médio - principal prova para ingresso ao ensino superior) ao afirmar que este exame não foi feito para corrigir desigualdades (LEMOS, 2020). Neste caso, a principal autoridade educacional do país afirma que é um exame excludente e não está preocupado com isso.

Essa exclusão é histórica e proposital, a construção da classe média brasileira se configura devido à modernização seletiva, em que esta classe explora a "ralé brasileira" (negros e mulatos mestiços) delegando atividades domésticas e pesadas a esses indivíduos (SOUZA, 2017). À ralé, negou-se a oportunidade de competir por uma nova realidade, colocando-a num patamar de extrema desigualdade com as outras classes (SOUZA, 2017). E ainda hoje essa desigualdade acaba se perpetuando, visto que, apesar de 53, $9 \%$ dos brasileiros serem negros ou pardos (IBGE, 2016), apenas 30\% da população universitária corresponde a negros e pardos (Instituto Nacional de Estudos e Pesquisas Educacionais Anísio Teixeira, 2017).

Apesar da Universidade brasileira ser responsável pelo desenvolvimento tecnológico no Brasil e defender a liberdade democrática, o cenário de exclusão permanece (CASTRO, 2019). Deste modo, os PUPs buscam combater a estrutura atual através do acesso aos mais altos níveis de educação (CASTRO, 2019). Dentro desse cenário existem alguns níveis de atuação dos PUPS:

- o oferecimento do pré-vestibular a pessoas sem condições financeiras de cursar um cursinho comercial, para que possam disputar uma vaga nas melhores universidades em condição de igualdade;

- atendimento aos grupos sistematicamente excluídos dos bancos universitários;

- dotar o aluno de elementos que o auxiliem a lidar com dificuldades que irá encontrar no seu cotidiano;

- incorporar no aluno uma visão questionadora da sociedade em que vive, procurando abordar e discutir temas que não estariam presentes numa educação escolar tradicional;

- realizar uma intervenção no vestibular procurando democratizá-lo e reduzir as desigualdades no Ensino Superior; (BACCHETTO, 2003, p. 103-104)

Nota-se que estes movimentos educacionais se preocupam com a democratização do acesso ao Ensino Superior através da formação de um estudante mais crítico. Tendo em mente que os PUPs são movimentos de Educação Popular, se a educação neste espaço não for crítica resultará em mais desigualdade, visto que, segundo Freire (2011), quando a educação não é libertadora o sonho do oprimido é se tornar opressor. Entretanto, existe a problemática da não existência de vagas suficientes nas Universidade para a população brasileira, então a luta é por uma Universidade pública e de qualidade para todos. Acima de tudo, a luta pela 
educação popular se faz por conquistas políticas no acesso, permanência, por aumento das quantidades de vagas no ensino superior público e construção de Universidades. Essa é a luta dos PUPs, uma luta de professorrs e estudantes, dos que foram excluídos da Universidade. Essa exclusão não ocorreu, necessariamente, por culpa destas instituições, pois é contraditório uma instituição que busca inclusão e diversidade ser excludente (CASTRO, 2019). Muito dessa culpa foi da tardia construção de Universidades no Brasil e da falta de políticas que promovessem essa expansão. Políticas que, a partir de 2003, começaram a ser ampliadas massivamente (NUNES, 2018).

Existe um vasto campo de pesquisas a serem desenvolvidas sobre PUPs, devido à pouca quantidade de trabalhos existentes sobre essa tema (RUPPENTHAL, 2019). Ressalta-se, então, a importância de ampliar os conhecimentos acerca destes movimentos educacionais. Estes espaços preocupam-se, também, com a formação de seus educadores, algo que tem sido evidenciado em diferentes pesquisas (SILVA, 2017; ROCHA, 2016; ALMEIDA, 2010). Neste sentido, existem discussões que podem ser promovidas de forma inédita sobre estes conhecimentos, mais especificamente na questão da contribuição para a formação de professores de Química.

Para pensar na formação de professores nos espaços de educação popular é necessário o enfoque na formação de sujeitos politizados, que são aqueles que consideram suas vidas num processo biográfico, histórico e coletivo, conforme apontaram Freire e Betto (2002). Desta forma, uma educação politizada será a que discutirá os problemas sociais, usando a ciência - química - como forma de problematizar a vida. Sendo imprescindível que os professores sejam formados para estarem atuando de acordo com tal perspectiva (RANGEL; PETRY, 2005). Concorda-se com Freire (2007) que ser professor não é vocação ou dom, este sujeito é formado ao longo de sua vida, sendo que a vivência em sociedade, incluindo a participação em movimentos sociais, contribui com sua formação.

Em consonância com Delizoicov, Angotti e Pernambuco (2011), este educador de química busca romper com uma visão da neutralidade da ciência, entendendo-a como atividade humana, sócio-historicamente determinada que está submetida a interesses, sejam internos ou externos a essa atividade. Infelizmente, a dimensão política da química tem sido negligenciada na formação de professores (MALDANER, 1999). Conhecimento este que deveria ser problematizado pensando em como esta ciência poderia contribuir com avanços tecnológicos, diminuindo riscos e desigualdades (SANTOS, 2011).

Ressalta-se que, dentro desta visão crítica de ensino, a autonomia da prática docente deve ser valorizada, o que também deve acontecer dentro dos PUPs. Em uma reunião do Projeto de Educação Comunitária Integrar, um PUP localizado em Florianópolis-SC, discutiu-se que o projeto incentiva explorar diversas maneiras do educador de atuar em sua atividade docente promovendo a liberdade deste em criar alternativas de como gostaria de lecionar (ROCHA, 2015a). O Integrar tem como um dos seus objetivos a formação de seus educadores (ROCHA, 2016). Algo que se concretizava em reuniões mensais, nas quais era requisitada a presença de todos professores, o que foi vivenciado pela autora deste trabalho, que atuou no projeto de 2014 a 2018.

Diante do que foi exposto e a partir do que foi desenvolvido numa dissertação de mestrado acerca das contribuições do Projeto de Educação Comunitária Integrar para a formação de professores de Química, descrevemos e discutimos aqui o resultado de uma pesquisa que buscou responder ao seguinte questionamento: Como o Pré-universitário Popular Projeto de Educação Comunitária Integrar pode contribuir com a formação de professores de química? 
Para isso, este trabalho está dividido em cinco seções. Esta primeira, introdutória, que busca contextualizar o que será discutido no trabalho. Uma sessão que discute os aspectos metodológicos no desenvolvimento da presente pesquisa. Nas duas seguintes, ocorre a discussão dos resultados das categorias analíticas "O papel do planejamento" e "O desenvolvimento das aulas", respectivamente. Por fim, apresentam-se as considerações finais.

\section{Percursos metodológicos}

Esta pesquisa foi realizada através de um estudo de caso com professores de Química do Projeto de Educação Comunitária Integrar que atuaram no projeto em 2017. O estudo de caso é adequado para estudar algo singular (LUDKE; ANDRÉ, 1986) e quando o pesquisador não tem controle sobre eventos inseridos na vida real (YIN, 2001). A escolha do ano 2017 foi estratégica, pois neste recorte temporal a equipe de Química do Integrar se propôs a sair de um ensino pautado em pura definição de conceitos e sendo um ano, também, de renovação do quadro de educadores de Química (RUPPENTHAL, 2017).

No início de 2017, havia oito educadores na equipe de Química, sendo uma delas a autora deste trabalho. Cabe ressaltar que esta é uma pesquisa participante de avaliação qualitativa, em consonância com a perspectiva defendida por Demo (2010). Para tanto, a metodologia para coleta dos dados foi feita através do Grupo Focal, no qual é realizada a discussão de um tema com os participantes da pesquisa (GATTI, 2005). Para a realização dessa discussão, conforme orienta Gatti (2005), foram elaboradas questões norteadoras (Apêndice 1). Uma das limitações encontrada para realização do Grupo Focal foi marcar um horário que todos pudessem participar dessa discussão. Como forma de tentar minimizar esta limitação, a discussão foi realizada através do aplicativo Skype e, mesmo assim, apenas seis dos oito educadores participaram da pesquisa. Estes professores possuem como ponto em comum ter participado do Integrar, entretanto, a sua formação inicial é diferente, como pode ser observado na tabela abaixo:

Tabela 1: Perfil dos professores do Integrar

\begin{tabular}{|c|c|c|}
\hline Curso & Cursando & Concluído \\
\hline $\begin{array}{c}\text { Licenciatura em Química e/ou Ciências } \\
\text { com habilitação em Química }\end{array}$ & 4 & 3 \\
\hline Bacharelado em Química & 1 & 1 \\
\hline Mestrado & 1 & 2 \\
\hline Doutorado & 1 & 1 \\
\hline
\end{tabular}

Fonte: RUPPENTHAL (2019).

A tabela acima descreve a formação dos educadores, mas não retrata a quantidade total dos mesmos, que são oito. Pois haviam educadores que já haviam concluído tanto bacharel quanto licenciatura, alguns que ainda cursavam o bacharel sem ter cursado a licenciatura, alguns que ainda cursavam, somente, a licenciatura. A análise da tabela acima possibilita a percepção de que a equipe de química do Integrar é composta por pessoas que estudaram ou estavam estudando Química (Licenciatura ou Bacharelado). Sendo que havia educadores que estavam cursando ou já cursaram pós-graduação (Mestrado e/ou Doutorado). 
Para análise dos dados coletados, através da gravação do áudio da discussão, optou-se pela Análise Textual Discursiva (ATD) de Moraes e Galliazi (2007), que consistiu em três etapas: a unitarização, a categorização e a comunicação. Na primeira etapa ocorreu a leitura do material de pesquisa buscando fragmentar o texto. Já na categorização, realizou-se a leitura flutuante dos fragmentos agrupando-os, neste caso, esta etapa resultou em duas categorias emergentes: "O papel do planejamento" e "O desenvolvimento das aulas". Por fim, ocorreu a produção de metatextos que expressam a visão do pesquisador com a análise, bem como a relação dos fragmentos com a categoria.

Para preservar a identidade dos participantes de acordo com o Termo de Consentimento Livre e Esclarecido, seus nomes foram trocados por cientistas negras, com o intuito de homenageá-las. O gênero do participante não foi levado em consideração, visto que para esta pesquisa não foi realizada análise por gênero. Sendo assim, todas as repostas dos participantes serão referidas no gênero feminino.

\section{O papel do planejamento}

O planejamento faz parte da atividade docente (VASCONCELLOS, 2002), no Integrar as educadoras ressaltaram que a discussão desta etapa era feita no coletivo:

Bom o que eu achava bastante interessante é que a gente se reunia para fazer né? O planejamento. E daí tinha uma troca esses momentos, inclusive quando por exemplo eu e Bessie Blount Griffen demos aula na mesma turma a gente se comunicava muito para preparar as aulas. (Annie Easley)

Eu acho assim, que na época que a gente fez, que a gente sentou e conversou foi bem importante, é fazer essa seleção e trabalhar por temas. E eu lembro que naquele ano que eu trabalhei dentro do Integrar, eu tentei seguir mais ou menos essa seleção prévia. E eu acho que durante o ano tentei mudar algumas coisas (Alice Ball)

Os excertos acima expressam a existência de diálogo entre as professoras para o planejamento, uma característica muito peculiar e ressaltada no Integrar: o posicionamento enquanto equipe. Na fala de Annie Easley, ela afirma que o planejamento era um momento de troca, o que pode ser interpretado como um momento de formação. Este aspecto está em consonância com Vasconcellos (2002), que destaca o momento do planejamento como um processo de construção do conhecimento entre os participantes da atividade.

Além da dimensão coletiva no planejamento do ensino, existe ainda a preocupação com considerar o educando enquanto parte do processo educativo, buscando valorizar suas ideias:

[...] também na entrevista você consegue conhecer muito da história do estudante. Então você já se prepara, você já tá conhecendo ele então futuramente nas tuas aulas você já vai lembrar aquela pessoa tem essa história de vida, tem essas dificuldades. Porque eles já falam isso na entrevista. Então acho que já fica mais fácil de você preparar e organizar as aulas futuramente. (Mae Jemison)

Então nesse segundo semestre o que eu fiz na verdade foi na primeira aula eu fiz na verdade uma dinâmica pra conhecer eles melhor e perguntei algumas coisas que eles tinham curiosidade ou gostariam de saber. Claro que né, a Química Orgânica é sobre drogas e tudo mais. Mas eu tentei pegar algumas coisas que eles tinham falado na primeira aula pra trazer nas outras aulas. Nem tudo eu consegui porque era pouco tempo, mas eu tentei fazer mais ou menos assim, uma dinâmica de diagnóstico. (Mamie Phipps Clark) 
Entender a realidade discente é necessário para que haja aprendizagem significativa, pensando no estudante como sujeito histórico e de aprendizagem (DELIZOICOV; ANGOTTI; PERNAMBUCO, 2011). Algo que parece ser almejado pelas educadoras, buscando considerar o conhecimento sobre a vida dos estudantes para o planejamento das atividades. Neste aspecto, vale ressaltar o Integrar enquanto movimento social e por isso mesmo existe a aprendizagem sobre as condições de vida de parte da população que participa do processo (GOHN, 2012). Neste caso, os excluídos do ensino superior e estudantes do Integrar.

Durante a discussão no grupo focal, algumas educadoras demonstraram interesse na avaliação da aprendizagem dos estudantes:

Pra mim quanto a seleção de conteúdos, no início quando eu entrei tinha feito um calendariozinho tentando colocar o máximo de conteúdos possíveis que seriam relacionados a minha frente que era físico-química. Era a parte de físico-química, mas logo eu vi que não ia funcionar e não ia dar para ter um ritmo de pré-vestibular padrão, assim de dar conteúdo de semana a semana independente se as pessoas estão aprendendo aquilo ou não. E aí mudando isso eu fiz uma seleção mais baseada no que seria mais frequente em prova, mas daí deixando o tempo mais livre no sentido de se precisassem oito semanas para trabalhar certo conteúdo, seria aquilo e aí excluía coisas que estaria mais pro final. (Jane Wright)

É a gente preferia ter certeza de que aquilo estava bem sedimentado, para prosseguir. As vezes a gente retomava, ao invés de passar para a próxima aula para planejar. (Annie Easley)

Nos fragmentos acima, as educadoras demonstram entendimento crítico que não é porque houve um momento de aula expositiva que ocorreu o aprendizado, entretanto as práticas das professoras parecem se aproximar da educação bancária pautada na memorização de conteúdos (FREIRE, 2011). Jane Wright, apesar de reorganizar o que iria trabalhar com os estudantes, aparenta apego à educação bancária, pensando como os estudantes irão memorizar os conteúdos de química para a prova do vestibular.

O campo da aprendizagem envolve questões inerentes ao educando e o planejamento adequado do momento da aula não pode garantir esta ação, mas pode favorecê-la (LOBATO, 2010). Apesar da aproximação com a educação bancária, houve algum avanço por parte das educadoras, visto que estas consideraram que existe a dimensão dependente dos educandos, distanciando-se de uma mera prática bancária, que considera o discente como mero depósito de conteúdo e, por ser um depósito, a transmissão garante a aprendizagem. Apesar do Integrar ser um projeto que se propõe a distanciar-se da educação bancária, apontar falhas que o aproximam dessa prática é importante para repensar a prática e avançar.

Diante dessa contradição, aponta-se que parece existir a vontade das educadoras de buscar uma aproximação com a educação libertadora:

Uma das vezes que a gente decidiu, acho que foi no começo de 2018 que a gente teve a reunião e foi decidido tirar as frentes da Química. Foi mais por temáticas. Acho que foi uma das melhores formas que a gente trabalhou assim, conceito. Que a gente buscava pegar mais o que provavelmente cairia no vestibular, mas tentar buscar um sentido maior que além de: ah vai cair no vestibular! (Mae Jemison)

E as vezes eu trazia algum texto tipo de notícia de site da internet de coisas que dava para relacionar com química ou era de química mesmo. E ai lia junto ou dava para eles lerem para comentar. (Jane Wright) 
No primeiro fragmento, Mae Jemison afirma que em uma reunião de equipe optou-se por trabalhar os conceitos da Química em formas de temáticas. Neste aspecto, existe mais de uma forma de abordar temas no ensino de ciências. Da sua fala, infere-se que a forma de abordagem é a inserção pontual de conceitos, visto que o enfoque é trazer um contexto para trabalhar um conceito. A inserção pontual conceitual que é definida por: "focam práticas realizadas em um determinado número de aulas enfocando blocos de conteúdos relacionados a um tema e que apresentam indicativos de cunho metodológico" (HALMENSCHLAGER; DELIZOICOV, 2017).

Ademais, outra forma de trabalho das educadoras, presente no fragmento acima, é através da discussão de conceitos utilizando notícias e vídeos. Em consonância com Delizoicov, Angotti e Pernambuco (2011), uma forma de inovar para o ensino de ciências é através de notícias, buscando apresentar um contexto no qual os conhecimentos científicos passam a ter algum significado. Para tanto, as educadoras buscam a inovação no ensino de química.

Nesta categoria, foi possível identificar a dedicação das professoras com o planejamento das atividades no Integrar, que buscam incluir o educando como parte ativa do processo de ensino. Como o planejamento foi pensado no coletivo, é, também, momento de formação para as educadoras envolvidas no processo. Entretanto, nem todas as professoras demonstraram se distanciar da educação bancária, especialmente na questão do apego ao conteúdo de Química que é pedido pelo vestibular, algo preocupante já que o Integrar se propõe a assumir uma prática libertadora.

\section{O desenvolvimento das aulas}

Nesta categoria, a análise será sobre o enfoque dado ao desenvolvimento das aulas, portanto envolvendo questões metodológicas. As educadoras buscaram em sua prática a experimentação para o Ensino de Química:

E eu as vezes me baseava em artigos do Química Nova na Escola pra tirar alguma experiência alguma coisa. (Alice Ball)

Quando eu dei aula eu acho que eu levei uns 2 (experimentos). Eles não necessariamente tinham muito a ver com o conteúdo e eu não sei se na época eu acertei em ter levado. Mas era mais para eles se animarem um pouquinho. Como era Química Orgânica as vezes eu levava um material, levava um experimento, e explicava do que era feito o material. Não sei se eu acertei na verdade. (Mamie Phipps Clark)

A experimentação é bastante discutida e utilizada no ensino de química como forma de aproximar a ciência dos discentes, porém muitas vezes é reduzida à atividade motivacional (GOLÇALVES; MARQUES, 2006). O fragmento de Mamie Phipps Clark expressa esta visão limitada sobre o uso de experimentos, entretanto ela questiona o acerto no uso do recurso. Este questionamento pode estar relacionado com o erro da motivação ser o único objetivo do uso de experimentos. Portanto, sugere-se como um objetivo mais adequado a esta atividade a aprendizagem dos conceitos envolvidos (GALIAZZI et al., 2001).

Como a experimentação pode contribuir com o aprendizado de Química, existem condições para esta seja desenvolvida pensando na questão dos possíveis riscos da atividade. A Química Verde1 (QV), em seu décimo 
segundo princípio, afirma que, para prevenção de acidades, as substâncias escolhidas deverão apresentar o menor potencial de risco possível para acidentes (ANASTAS; WARNER, 1998). Afastando-se deste princípio, uma atividade desenvolvida no Integrar resultou num acidente:

É lá era complicado de fazer experimento, eu lembro que uma vez, não sei se tu tava Mamie Phipps Clark. Marie Maynard Daly foi fazer um experimento e pegou fogo a mochila dela. [...] Eu nunca esqueço, acho que depois a gente traumatizou um pouco de levar experimento para lá. (Alice Ball)

Analisando este fragmento, percebe-se um trauma decorrente do episódio interferindo na prática da professora. Infelizmente, quando se trata da formação inicial do professor de Química, a articulação entre a Química e a questão ambiental tem sido apontada como insuficiente (LEAL; MARQUES, 2008). Deste modo, infere-se que desconsiderar a periculosidade no experimento pode ter sido uma lacuna na formação inicial de Alice Ball. Com relação à formação de professores de química, Gonçalves et al. (2017) aponta que a inclusão de métricas de QV na formação inicial de licenciado em Química pode promover a apropriação de conteúdos atitudinais sobre o meio ambiente e que estes podem afetar a escolha de experimentos mais adequados para serem utilizados na educação básica.

Outra forma de utilizar a experimentação no ensino de química é através da utilização de vídeos:

Ah eu utilizava diferentes livros didáticos, também procurava coisa na internet, artigo, vídeo, as vezes a gente não conseguia fazer o experimento por conta do espaço, ai eu procurava trazer em forma de vídeo. (Annie Easley)

Neste fragmento, a educadora ressalta que o ambiente não era propício para a realização de experimentos, apresentando o vídeo como uma alternativa, apesar de desvantagens como a inexistência de erros e a falta de vivência no laboratório (SANTOS et al, 2010). No Projeto Integrar, percebe-se a inclusão da atividade experimental no ensino de ciências, seja através de vídeos ou do uso em sala de aula. E isto é parte importante do discurso das ciências que busca a inclusão da atividade experimental em sala de aula (GALIAZZI; GONÇALVES, 2004).

Como o ingresso no ensino superior é um dos objetivos do Integrar (ROCHA, 2015b), existe preocupação com os conceitos exigidos na prova do vestibular:

Que a gente buscava pegar mais o que provavelmente cairia no vestibular, mas tentar buscar um sentido maior que além de: ah vai cair no vestibular! Tem todo um sentido fora pra familiarizar o próprio estudante com aquele conteúdo, mas não tirando o peso do vestibular e a sua importância também. (Mae Jemison)

Este fragmento demonstra distanciamento de um ensino de química crítico. Em consonância com Delizoicov, Angotti e Pernambuco (2011), o conceito científico é o ponto de chegada e o ponto de partida seria a realidade, as situações que possuem significado ao estudante. Entretanto, é possível perceber que existe um esforço da equipe de química para buscar significado para os conceitos químicos estudados. Neste sentido, ressalta-se que é necessário manter o olhar no que é exigido pelo vestibular, pois de nada adiantaria uma consciência crítica sobre a exclusão que o vestibular causa se a química não contribuir para mudar essa realidade, buscando auxiliar no ingresso na universidade, mesmo utilizando uma prova. Isto pode ser articulado com o que é discutido por Demo (2010, p. 72): “Consciência crítica da pobreza ainda é pobreza. A coisa começa realmente a valer a partir do momento que se assume o compromisso de mudar a situação criticamente entendida.." Neste sentido, é possível entender o porquê de as educadoras manterem os olhos no vestibular. 
Nesta sessão, as professoras demonstraram diferentes metodologias para o trabalho docente. Destaca-se a questão da experimentação no ensino de química. Em vários relatos as educadoras apontaram centralidade para este aspecto, mas ao mesmo tempo abordaram algumas limitações que ocorrem dentro do Integrar. No caso do Projeto Integrar, existe a superação da experimentação para comprovação da teoria, aproximando-se de algumas características de uma visão discutida por Gonçalves (2009): a perspectiva dialógica problematizadora. Tendo em vista que existe preocupação das professoras com centrar o ensino no educando, através da apreensão do conhecimento prévio discente, o que foi discutido na sessão anterior, para depois desenvolver a atividade experimental. 


\section{Considerações finais}

A análise das entrevistas, de maneira geral, apontou que o Integrar, o PUP estudado, tem contribuído com a transição de pensamento das educadoras passando de uma perspectiva tradicional para uma de caráter mais crítico. Entretanto, ainda existem falhas que apontam à existência de uma perspectiva tradicional na prática das educadoras do projeto.

A existência de diálogo promoveu um planejamento coletivo para o ensino de Química no Integrar. E esse planejamento no coletivo possibilitou trocas de experiências, articulando-o com um momento de formação para as participantes, como ressalta Vasconcellos (2002) quando afirma que o planejamento também pode ser uma atividade de formação.

Ademais, conhecer o educando era imprescindível para o planejamento das atividades, reconhecendo este sujeito como parte importante do processo educativo. Entretanto, os conceitos químicos trabalhados com foco no vestibular demonstram uma característica em consonância com a educação bancária, o que precisa ser discutido dentro do movimento social. Apesar disso, aponta-se que o Integrar contribuiu para que as educadoras pensem no educando enquanto centro do processo educativo.

Com relação à experimentação, aponta-se a existência de erros na utilização da estratégia. Entretanto, as próprias educadoras apontaram que não utilizaram o recurso de forma adequada, algo que demonstra reflexão sobre a própria prática, o que é um tipo de formação. Neste sentido, finaliza-se este trabalho apontando possibilidades de melhorar a prática docente do Projeto e as contribuições para a formação de professoras. Por fim, de acordo com este estudo de caso, os PUPs contribuem com a formação de professores de Química.

AGRADECIMENTOS: Ao CNPq pela bolsa de mestrado e ao Projeto de Educação Comunitária Integrar pela possibilidade de fazer a pesquisa. 


\section{REFERÊNCIAS}

ALMEIDA, M. D. de. A formação de professores no curso Prévestibular Comunitário Prof. Wellington Ricardo. 2010. Dissertação (Mestrado em Educação, Cultura e Comunicação em Periferias Urbanas) - Faculdade de Educação da Baixada Fluminense, Universidade do Estado do Rio de Janeiro, Duque de Caxias, 2010.

ANASTAS, P.T.; WARNER, J.; Green Chemistry: Theory and Practice, Oxford University Press: Oxford, 1998.

BACCHETTO, J. G. Cursinhos pré-vestibulares alternativos no município de São Paulo (1991-2000): a luta pela igualdade no acesso ao ensino superior. Dissertação (Mestrado em Educação) - Faculdade de Educação da USP, Universidade de São Paulo, São Paulo, 2003.

BRASIL. Lei n ${ }^{\circ} 12711$, de 29 de agosto de 2012. Dispõe sobre o ingresso nas universidades federais e nas instituições federais de ensino técnico de nível médio e dá outras providências. Brasília, 2012.

CASTRO, C. A. de. Cursinhos alternativos e populares: geografia das lutas. 1. ed. Curitiba: Appris, 2019. 291 p.

CHAVES, S. N. Por que Ensinar Ciências Para as Novas Gerações?: Uma Questão Central Para a Formação Docente. Contexto e Educação, [S.I.], v. 22, n. 77, p.11-24, 2007.

DELIZOICOV, D.; ANGOTTI, J. A.; PERNAMBUCO, M. M. Ensino de Ciências: fundamentos e métodos. 4. ed. São Paulo: Cortez, 2011. 364 p.

DEMO, P. Avaliação qualitativa. 10. ed. Campinas, SP: Autores Associados, 2010. 85 p.

FREIRE, P. Pedagogia do Oprimido. 59. ed. Rio de Janeiro: Paz e Terra, 2011. 256 p.

FREIRE, P. Política e Educação. 8. ed. Indaiatuba: Villa das Letras, 2007. 128 p.

FREIRE, P; BETTO, F. Essa escola chamada vida: depoimentos ao repórter Ricardo Kotscho. 14. ed. São Paulo: Ática, 2002. 95 p.

GALIAZZI, M. C. et al. Objetivos das atividades experimentais no ensino médio: a pesquisa coletiva como modo de formação de professores de Ciências. Revista Ciência \& Educação, v. 7, n. 2, p. 249-263, 2001.

GALIAZZI, M. C.; GONÇALVES, F. P. A natureza pedagógica da experimentação: uma pesquisa na licenciatura em química. Química Nova, v. 27, n. 2, p. 326-331, 2004.

GATTI, B. A. Grupo focal na pesquisa em Ciências Sociais e Humanas. 1. ed. Brasília: Líber Livro Editora, 2005. $77 \mathrm{p}$.

GOHN, M. da. G. Movimentos sociais e educação. 8. ed. São Paulo: Cortez, 2012. 128 f.

GONÇALVES, F. P. A problematização das atividades experimentais no desenvolvimento profissional e na docência dos formadores de professores de química. Tese (Doutorado) - Programa de Pós-Graduação em Educação Científica e Tecnológica, Universidade Federal de Santa Catarina, Florianópolis, 2009. 
GONÇALVES, F. P. et al. La dimensión ambiental de la experimentación en la enseñanza de la química: consideraciones sobre el uso de la métrica holística «estrella verde». Educación Química, v. 28, n. 2, p.99-106, 2017

GONÇALVES, F. P.; MARQUES, C.A. Contribuições pedagógicas e epistemológicas em textos de experimentação no ensino de química. Investigações em Ensino de Ciências, v. 11, p. 219-238, 2006.

HALMENSCHLAGER, K. R.; DELIZOICOV, D. Abordagem temática no ensino de ciências: caracterização de propostas destinadas ao ensino médio. Alexandria, v. 10, n. 2, p.305-330, nov. 2017.

IBGE. Síntese de indicadores sociais: uma análise das condições de vida da população brasileira. Rio de Janeiro: IBGE, 2016. 146 p.

INSTITUTO NACIONAL DE ESTUDOS E PESOUISAS EDUCA CIONAIS ANÍSIOTEIXEIRA. Sinopse Estatística da Educação Superior 2016. Brasília: Inep, 2017. Disponível em: <http://portal.inep.gov.br/basica-censo-escolar-sinopse-sinopse>. Acesso em: 15 maio 2018.

LEAL, A. L.; MARQUES, C. A. O Conhecimento Químico e a Questão Ambiental na Formação Docente. Química Nova na Escola, v. 29, p. 30-34, 2008.

LEMOS, lara. Em reunião com senadores, Weintraub diz que Enem não foi feito para corrigir injustiças. Folha de São Paulo. São Paulo. 05 maio 2020. Disponível em: <https://www1.folha.uol.com.br/educacao/2020/05/ em-reuniao-com-senadores-weintraub-diz-que-enem-nao-foi-feito-para-corrigir-injusticas.shtml>. Acesso em: 07 maio 2020.

LOBATO, A. C. Conceito x definição. 2010. Disponível em: http://www.educacaopublica.rj.gov.br/biblioteca/ educacao/0250.html. Acesso em: 04 abr. 2019.

LÜDKE, M; ANDRÉ, M. E. D. A. Pesquisa em educação: abordagens qualitativas. 1. ed. São Paulo: EPU, 1986. $100 \mathrm{p}$.

MALDANER, O. A. A pesquisa como perspectiva de formação continuada do professor de química. Química Nova, São Paulo, v. 22, n. 2, p. 289-292, 1999.

MORAES, R.; GALIAZZI, M. C. Análise Textual Discursiva. ljuí: Editora Unijuí, 2007. 224 p.

NUNES, H. F. P. Políticas Públicas para a expansão do ensino superior no Brasil entre 2003-2014: Reflexos na região sudoeste do Paraná. Dissertação (Mestrado em Geografia) - Programa de Pós-Graduação em Geografia, Universidade Estadual do Oeste do Paraná, Francisco Beltrão, 2018.

RANGEL, M.; PETRY, P. Educação política de professores: conceitos e importância. Educação, Porto Alegre, V. 56, n. 2, p. 352-360, 2005.

ROCHA, K. C. A perspectiva formativa dos trabalhadores estudantes no Projeto de Educação Comunitária Integrar no contexto do ensino de Geografia. 2016. 260 f. Dissertação (Mestrado em Geografia) - Curso de Programa de Pós-graduação em Geografia, Universidade Federal de Santa Catarina, Florianópolis, 2016. 
ROCHA, K. C. Demanda de formação dos professores. IN: INTEGRAR, Projeto de Educação Comunitária. Ata da Assembleia Geral Ordinária nº05/2015. Projeto Integrar: Florianópolis, 2015a.

ROCHA, K. C. Formação sobre Educação Popular. IN: INTEGRAR, Projeto de Educação Comunitária. Ata da Assembleia Geral Ordinária n 008/2015. Projeto Integrar: Florianópolis, 2015b.

RUPPENTHAL, N. Apresentação das equipes. IN: INTEGRAR, Projeto de Educação Comunitária. Ata da Assembleia Geral Ordinária nº 003/2017. Projeto Integrar: Florianópolis, 2017.

RUPPENTHAL, N. Contribuições do Projeto de Educação Comunitária Integrar para a formação de professores de Química. Dissertação (Mestrado) - Programa de Pós-Graduação em Educação Científica e Tecnológica, Universidade Federal de Santa Catarina, Florianópolis, 2019.

SILVA, J. O. da. Desafio pré-vestibular UFPEL: a extensão universitária na formação de professores de ciências da natureza. 2017. 163 f. Dissertação (Mestrado) - Curso Pós-graduação em Educação em Ciências: Química da Vida e Saúde, Universidade Federal do Rio Grande do Sul, Porto Alegre, 2017.

SANTOS, R. I. et al. Experimentação mediante vídeos: possibilidades e limitações para a aplicação em aulas de Química. In: ENCONTRO NACIONAL DE ENSINO DE QUÍMICA, 10., 2010, Brasília. Anais... Disponível em: <http://www.sbq.org.br/eneq/xv/resumos/R0641-2.pdf>. Acesso em: 30 março 2019

SANTOS, W. L. P. A Química e a formação para a cidadania. Educ. quím. [S. I.] v. 22, n. 4, p. 300-305, 2011.

SOUZA, J. A elite do atraso: da escravidão à Lava Jato. 1. ed. Rio de Janeiro: Leya, 2017.

VASCONCELLOS, C. dos S. Projeto de Ensino-Aprendizagem. In: VASCONCELLOS, C. dos S. Planejamento: Projeto de Ensino-Aprendizagem e Projeto Político-Pedagógico. 10. ed. (Cadernos Pedagógicos do Liberdad, v. 1) São Paulo. Liberdad, 2002. Cap. 3. p. 95-113.

YIN, R. K. Estudo de caso: planejamento e métodos 2. ed. Porto Alegre: Bookman, 2001. 206 p. 


\section{Apêndice}

Apesar que já nos conhecemos, vamos fazer uma breve rodada de apresentação para descontrair um pouco e também conhecer algo mais sobre os outros colegas. Mas fiquem à vontade para dizer o que quiserem, inclusive sobre a expectativa de vocês com esse encontro de pesquisa. Tempo para diálogos: 20 min

Para uma rodada de apresentação, vou fazer uma pergunta para que cada um dê a dimensão de sua história de atuação e envolvimento com o INTEGRAR.

1.Conte por qual período de tempo você atuou/atua no Integrar como educador, qual a sua formação (bacharel/ licenciatura) - se já concluiu ou se está cursando.

\section{Roda de conversa:}

A partir de agora farei algumas poucas perguntas algumas mais específicas e outras mais abertas ou gerais. Seria legal que todos comentassem sobre esses questionamentos e que a conversa fomentasse a discussão entre vocês todos. Meu papel será apenas de organizadora das falas, portanto de ajudante e não de juíza ou fiscal, absolutamente de nada. Fiquem à vontade para expor suas ideias e as experiências que considerem importante sobre os temas que vou "provocar" através das perguntas.

1. Conte o que motivou você a participar do Integrar enquanto educador de química e também o que contribuiu para a sua permanência no projeto.

2. Relate como foi feita a seleção de conteúdos químicos trabalhados em sala de aula, ou seja, qual critério foi adotado? Você considerou importância haver essa seleção prévia de conteúdos e você a seguiu completamente quando ministrou aulas?

3. Em relação aos materiais didáticos e/ou textos pedagógicos utilizados no planejamento das aulas de Química, como é o processo de escolha e/ou elaboração destes?

4. A diversidade dos sujeitos na composição da turma trouxe a você professor/a algumas dificuldades no desenvolvimento dos conceitos de química em sala? Poderia exemplificar quais e como você resolveu didática e metodologicamente essas dificuldades?

5. Qual a importância da divulgação do Projeto Integrar nas comunidades e o que tem sido feito para isso acontecer?

6. Qual a importância das entrevistas de seleção dos futuros educandos do Projeto Integrar e como isso se relaciona com a aula de Química?

7. Qual a importância e singularidade de Projetos como o Integrar na luta pelo acesso e permanência ao Ensino Superior?

RUPPENTHAL, N.; MARQUES, C. A.; A formação de professores de Química num pré-universitário popular: um estudo de caso do projeto de educação comunitária integrar. Formação Docente - Revista Brasileira de Pesquisa sobre Formação de Professores. Belo Horizonte. Vol. 13, no. 26 (p. 117-132) 31 ago. 2021. ISSN: 2176-4360. DOI https:// doi.org/10.31639/rbpfp.v13i27.371 
